\title{
Histone deacetylase inhibitors in cancer therapy. A review
}

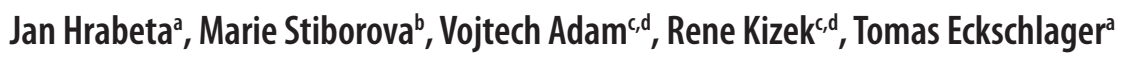

\begin{abstract}
Background. Despite recent success toward discovery of more effective anticancer drugs, chemoresistance remains a major cause of treatment failure. There is emerging evidence that epigenetics plays a key role in the development of the resistance. Epigenetic regulators such as histone acetyltransferases (HATs) and histone deacetylases (HDACs) play an important role in gene expression. The latter are found to be commonly linked with many types of cancers and influence cancer development. Overall, histone acetylation is being investigated as a therapeutic target because of its importance in regulating gene expression. This review summarizes mechanisms of the anticancer effects of histone deacetylase (HDAC) inhibitors and the results of clinical studies.

Results. Different HDAC inhibitors induce cancer cell death by different mechanisms that include changes in gene expression and alteration of both histone and non-histone proteins. Enhanced histone acetylation in tumors results in modification of expression of genes involved in cell signaling. Inhibition of HDACs causes changed expression in 2-10\% of genes involved in important biological processes. The results of experiments and clinical studies demonstrate that combination of HDAC inhibitors with some anticancer drugs have synergistic or additive effects.

Conclusions. Even though many biological effects of HDAC inhibitors have been found, most of the mechanisms of their action remain unclear. In addition, their use in combination with other drugs and the combination regime need to be investigated. The discovery of predictive factors is also necessary. Finally, a key question is whether the pan-HDAC inhibitors or the selective inhibitors will be more efficient for different types of cancers.
\end{abstract}

Key words: chromatin remodeling, histone acetylation, histone deacetylases, histone deacetylase inhibitors, combined treatment modalities, mechanisms of combined treatment

Received: July 3, 2013; Accepted with revision: November 12, 2013; Available online: November 21, 2013

http://dx.doi.org/10.5507/bp.2013.085

a Department of Pediatric Hematology and Oncology, $2^{\text {nd }}$ Faculty of Medicine, Charles University in Prague and University Hospital Motol, Prague, Czech Republic

${ }^{b}$ Department of Biochemistry, Faculty of Science, Charles University in Prague, Prague

'Department of Chemistry and Biochemistry, Faculty of Agronomy, Mendel University in Brno, Brno

${ }^{d}$ Central European Institute of Technology, University of Technology, Brno

Corresponding author: Tomas Eckschlager, e-mail: tomas.eckschlager@lfmotol.cuni.cz

\section{INTRODUCTION}

During the last few decades, several approaches have been applied in an effort to discover new more effective anticancer drugs. As a result, many promising compounds have been investigated. However, chemoresistance that may arise during chemotherapy is one of the main causes of failure of treatment. Epigenetic changes are emerging as part cause of the chemoresistence. These are the changes in gene expression or cellular phenotype caused by mechanisms other than changes in DNA sequence. They include changes in DNA methylation and chromatin remodeling, RNA transcripts and their encoded proteins, expression of non-coding RNAs, posttranslational changes in chromatin and mRNA regulation. Of these, histone acetylation and deacetylation have been investigated as therapeutic targets because of their importance in regulation of gene expression. Changes in histone acetylation influence chromatin condensation and these alterations influence gene transcription ${ }^{1}$. The balance between histone transacetylases and deacetylases is often damaged in cancer, leading to changed expressions of tumor suppressor genes and/ or proto-oncogenes ${ }^{1,2}$.
Enzymes catalyzing histone acetylation and deacetylation

Modification of histones by acetylation affects transcription by changing the structure of chromatin that modulates the accessibility of transcription factors to their target DNA and it plays an important role in regulation of expression ${ }^{3}$. Additionally, acetylation and/or deacetylation of non-histone proteins modify many important cell functions ${ }^{4}$.

The acetylation state of histones and other proteins is maintained by histone acetyltransferase (HAT) and histone deacetylase (HDAC) enzymes. HATs catalyze the transfer of an acetyl group from acetyl-CoA to lysine residues in proteins and HDAC removes it ${ }^{5}$. Depending on the mechanisms of removing the acetyl group, HDACs can be divided into two distinct families. The "classical family" comprises $\mathrm{Zn}^{2+}$-dependent HDACs, the second family of HDACs depends in catalysis on $\mathrm{NAD}^{+}$and subsequently, $O$-acetyl-ADP-ribose and nicotinamide are formed as a result of the acetyl transfer ${ }^{6}$. Furthermore, based on the homology to their yeast analogues, HDACs are divided into four classes. Class I, located in the nucleus, includes HDACs 1, 2, 3 and 8. HDACs 4, 5, 7 and 9 are members of class IIa, while isoforms 6 and 10 that are located both 
in the cytoplasm and nucleus are classified as class IIb of HDACs. Class IV, which exhibits features of class I and II, includes only HDAC11. NAD ${ }^{+}$-dependent homologues 1-7 of the yeast Sir2 proteins (sirtuins) are designed as class III of HDACs, and have mono-ADP-ribosyltransferase activity. HATs, "functional opponents" of HDACs, are divided into Gcn5/PCAF $N$-acetyltransferases (GNATs) and MYST HATs. Although these two groups of HATs are the major enzymes catalyzing $N$-acetyltransferase activity, other proteins also exhibit this acetylase activity ${ }^{7}$.

\section{Histone deacetylases and cancer}

HDACs class I and II levels vary in different cancer cells. HDAC 1 is overexpressed in prostate and gastric cancers, where it signalizes poor prognosis, as well as in lung, esophageal, colon and breast cancers ${ }^{8-10}$. High levels of HDAC2 have been found in colorectal, cervical and gastric cancers ${ }^{11,12}$. In addition, HDAC 3 is overexpressed in gastric, prostate and colorectal cancer ${ }^{13}$, and high expression of HDAC1 and 2 correlates with reduced patient survival in colorectal carcinomas ${ }^{14,15}$. HDAC6 is highly expressed in breast cancer, HDAC8 is over-expressed in neuroblastoma cells and its overexpression correlates with metastasis and advanced stage of disease with poor prognosis. Expression of HDAC11 is increased in rhabdomyosarcoma ${ }^{5,16,17}$. miR-449 that targets HDAC1 was identified in prostate cancer ${ }^{18}$ and in hepatocellular carcinoma low levels of miR-22, which targets HDAC4, correlated with poor prognosis ${ }^{19}$. Both diffuse large B-cell lymphomas (DLBCL) and peripheral T-cell lymphomas exhibit HDAC1, 2 and 6 overexpression ${ }^{20}$, whereas Hodgkin's lymphomas display increased HDAC 1, 2 and 3 levels ${ }^{21}$. In Waldenstrom macroglobulinemia, the upregulation of miR-9* results in HDAC4 and 5 dowregulation ${ }^{22}$.

Class III HDACs play an important role in carcinogenesis. Some act as antioncogenes while others influence tumors by controlling the cell metabolism ${ }^{22}$. Decreased activities of HDACs are associated with suppressed tumor cell development and growth ${ }^{23,24}$. Moreover mutations of HDAC4 have been identified in breast cancer samples ${ }^{25}$ and mutation of HDAC2 that cause protein truncation was found in human epithelial cancer cell lines ${ }^{26}$.

\section{Histone deacetylase inhibitors}

The results from various studies indicate that HDAC inhibitors increase the anticancer efficacy of additional therapy modalities and they therefore would be very efficient in the clinic together with other anticancer treatment modalities including ionizing radiation and/or chemotherapy. For this reason, investigation of the clinical application of HDAC inhibitors has increased with over 490 clinical trials for cancer and a few for other disease $^{27}$. Namely, HDAC inhibitors have also be found to be effective for treatment of other diseases. Some HDAC inhibitors have antimalarial properties and are studied as new possible drugs for the treatment of malaria ${ }^{28}$. There is also some evidence that HDAC pan-inhibitors and HDAC III inhibitors possess anti-inflammatory effects in models of asthma ${ }^{29}$.
Here, we describe HDAC inhibitors, the mechanisms of their actions and we discuss combination therapies with anti-tumor drugs. HDAC inhibitors may be both specific against only some HDACs (HDAC isoform-selective inhibitors) or against all types of HDACs (pan-inhibitors). They can be classified according to their chemical structure into four groups: 1) hydroxamic acids; 2) aliphatic acids; 2) benzamides; 4) cyclic tetrapeptides ${ }^{1}$.

1) Hydroxamic acids trichostatin A (TSA), vorinostat (suberoylanilide hydroxamic acid, SAHA) which was approved by the FDA as the first HDAC inhibitor for the treatment of relapsed and refractory cutaneous T-cell lymphoma (CTCL) ( ref. $^{30}$ ), belinostat (PXD-101) and panobinostat (LBH589) are pan-HDAC inhibitors.

2) The aliphatic acids [valproic acid (VPA), butyric acid and phenylbutyric acid] are only weak inhibitors of HDAC I and IIa (ref. ${ }^{31}$ ).

3) Benzamides that include entinostat (SNDX-275, MS-275) and mocetinostat (MGCD0103) are isoform selective inhibitors of HDAC I and mocetinostat inhibits also IV HDAC (ref. ${ }^{32}$ ).

4) The cyclic tetrapeptides, inhibitors of class I HDACs (romidepsin inhibits also HDAC 4 and 6), are cyclic hydroxamic acids containing peptides: romidepsin (depsipeptide, FK228, FR901228), apicidin and trapoxinand. Of these, romidepsin that was approved by the FDA and the EuMedicines Agency to treat CTCL and peripheral $\mathrm{T}$ cell lymphomas, is most effective ${ }^{33}$. It is a prodrug which is activated to a metabolite that chelates the zinc ions in the active center of the HDAC of class I (ref. ${ }^{34}$ ).

\section{MECHANISMS OF HISTONE DEACETYLASE INHIBITOR-INDUCED CELL DEATH}

Different HDAC inhibitors induce death of cancer cells by different mechanisms that include changes in gene expressions and alterations of both histone and non-histone proteins. Enhanced histone acetylation in a variety of tumors results in modification of expression of the genes involved in cell signaling. Inhibition of HDACs causes changed expression of approximately $2-10 \%$ of genes involved in several biological processes such as cell cycle arrest and apoptosis induction ${ }^{35}$. Many genes contributing to the regulation of the cell cycle and apoptosis were found to be modified by HDAC inhibition ${ }^{36,37}$. Moreover some HDAC inhibitors have antiangiogenic effects ${ }^{38}$. Mechanisms of actions of HDAC inhibitors are summarized in Fig. 1.

\section{Histone deacetylase inhibitors, cell cycle arrest and differentiation.}

The most important mechanism of cell cycle arrest induced by HDAC inhibitors seems to be increased expression of gene CDKN1A (p21) encoding the p21 protein that blocks the formation of dimers from cyclins and cyclin dependent kinases. This leads to arrest of the cell cycle and to induction of cell differentiation ${ }^{39}$. The expression of p21 is tightly controlled by the tumor suppres- 


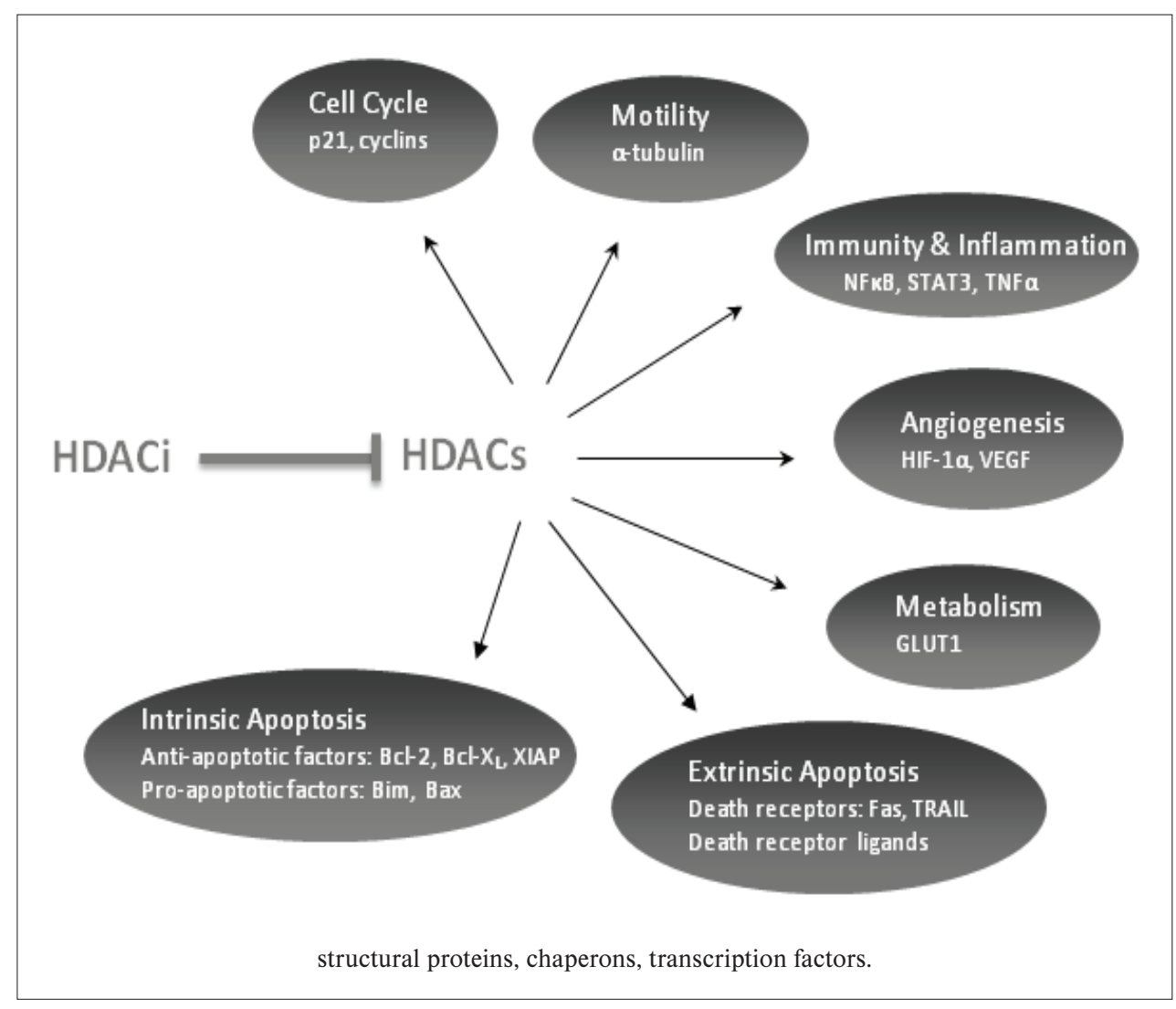

Fig. 1. Scheme of mechanisms of HDAC inhibitors action.

sor protein $\mathrm{p} 53$ that interacts with a Sp1 site of the $\mathrm{p} 21$ promoter, competing with HDAC1 which decreases transcription of p21 (ref. ${ }^{40}$ ). In cells treated with HDAC inhibitors, the HDAC1 protein is released from the Sp1 site, and this causes increase in p21 expression. Furthermore, HDAC inhibition stabilizes protein p53 by its acetylation $^{41}$. Elevated acetylation of histones located close to the $\mathrm{p} 21$ promoter also facilitates the access of transcription factors. HDAC inhibitors can also repress expression of cyclins D and A (ref. ${ }^{42}$ ). For clinical practice, another important feature of HDACi which could find its place in cancer therapy, is regulation of cell differentiation through activation of ERK. VPA has been shown to enhance DNA binding and transactivation activity of the AP-1 transcription factor by ERK activation and acts as a potent inducer of differentiation of several types of transformed cells. It increases expression of c-Jun and c-Jun phosphorylation in SH-SY5Y neuroblastoma cells ${ }^{43}$. The latter feature is required to direct cellular differentiation of poorly differentiated PC12 rat pheochromocytoma cells ${ }^{44}$.

\section{Histone deacetylase inhibitors and apoptosis}

HDAC inhibitors induce apoptosis in tumor cells by regulation of expression of proapoptotic and antiapoptotic genes $^{45}$. Mechanisms by which different HDAC inhibitors induce apoptosis include activation of both extrinsic and intrinsic apoptotic pathways. HDAC inhibitors have been demonstrated to influence death receptors and their ligands ${ }^{46}$. HDAC inhibitor-induced apoptosis has also been demonstrated to be associated with activation of the intrinsic pathway ${ }^{45}$. It can be concluded that in tumor cells exposed to HDAC inhibitors proapoptotic genes involved in the extrinsic and intrinsic apoptotic pathways are up-regulated, while expression of antiapoptotic genes is reduced ${ }^{12}$. Moreover, increased reactive oxygen species (ROS) levels that induce apoptosis were found in cancer cells treated with HDAC inhibitors but not in nonmalignant ones treated by same drugs. Inhibition of caspases does not block HDAC inhibitor induced cell death. This means that HDAC inhibitors also induce non-caspase types of cancer cell death ${ }^{47,48}$. Two mechanisms responsible for induction of oxidative stress by HDAC inhibitors may be damage to mitochondria and modulation of cellular antioxidants ${ }^{49}$.

HDAC inhibitors can also induce cell death in apoptosis resistant cells. One possible mechanism of non-apoptotic cell death induced by HDAC inhibitors is induction of autophagy. For example, FK228, an HDAC class I inhibitor and HDAC1 siRNA induce autophagy in HeLa cells in vitro ${ }^{50}$. SAHA caused tumor growth slowdown of glioblastoma xenografts in mice in which it induced autophagy. This HDAC inhibitor increased formation of intracellular acidic vesicle organelles, recruited LC3-II to the autophagosomes, potentiated Beclin 1 protein levels and reduced p62. SAHA triggered autophagy through the downregulation of AKT-MTOR signaling. Inhibition of SAHA-induced autophagy by chloroquine has synergistic effects that further increase apoptosis ${ }^{51}$. 
Histone deacetylase inhibitors and cell signaling pathways

An important mechanism of the anticancer effect of HDAC inhibitors is regulation of cell differentiation by activation of some protein kinases [mitogen-activated protein kinases (MAPK), c-Jun Nterminal kinase (JNK) and p38] that modulate cell growth, differentiation and apoptosis. HDAC inhibitors increase expression of c-Jun and its phosphorylation in several cancer cells ${ }^{43}$. VPA and natrium butyrate also affect Wnt signaling that is important in various malignancies, by phosphorylation of glycogen synthase kinase-3 $\beta$ (GSK-3 $\beta$ ) (ref. ${ }^{49,52}$ ). HDAC inhibitors also induce the expression of some enzymes involved in the proteasomal degradation pathway ${ }^{53}$.

\section{Histone deacetylase inhibitors and angiogenesis and cellular stress response pathways}

HDAC inhibitors can decrease angiogenesis by downregulation of vascular endothelial growth factor (VEGF) and endothelial nitric oxide synthase (eNOS) (ref. $\left.{ }^{54}\right)$. VPA has been demonstrated to enhance expression of the antiangiogenic proteins thrombospondin- 1 and activin $\mathrm{A}$ and to downregulate proangiogenic basic fibroblast growth factor $^{55}$. We found that VPA and trichostatin A decrease formation of the capillary tubes of human vascular endothelial cells but they do not induce apoptosis of those cells (unpublished results). In addition, treatment of cells with HDAC inhibitors caused degradation of HIF-1 $\alpha$ (hypoxia inducible factor), a proangiogenic transcription factor ${ }^{56}$.

Hypocetylation of the chaperone Hsp90 protects its client proteins such as bcr/abl or ErbB2 from degradation $^{57}$. In addition, hyperacetylation of Hsp90 induced by HDAC inhibitors reduces the chaperone association with its cancer-related client proteins, resulting in their proteasomal degradation ${ }^{57}$.

\section{COMBINATION OF HISTONE DEACETYLASE INHIBITORS WITH OTHER THERAPEUTIC REGIMENS}

The results from in in vitro and in vivo experiments using various cancer cells have demonstrated that combination of HDAC inhibitors with a variety of anticancer drugs have synergistic or additive effects ${ }^{58}$. Chemotherapeutic combinations with HDAC inhibitors have also been used in clinical trials ${ }^{59}$. Several types of therapies have been investigated in combination with HDAC inhibitors.

1) HDAC inhibitors were combined with other epigenetic modifiers. Inhibitors of DNA methyl transferases 5-azacytidine (azacitidine) and 5-aza-2'-deoxycytidine (decitabine) had increased antitumor effects when used with HDAC inhibitors ${ }^{60-64}$. Decitabine and VPA both induced apoptosis and the combination increased their effects both in vitro and in vivo ${ }^{65,66}$. Co-treatment of prostate, pancreatic tumor, acute myelogenous leukemia (AML) AML1/ETO-positive and non small cell lung cancer (NSCLC) cells with trichostatin A and decitabine synergistically induced apoptosis ${ }^{63,64,67,68}$. In addition, an inhibitor of histone demethylases (tranylcypromine) and vorinostat showed synergistic enhancement of apoptosis in glioblastoma cells ${ }^{45}$.

2) Promising results have been reported for combinations of HDAC inhibitors and ROS-generating agents. One such agent, adaphostin, increases entinostat and vorinostat induced apoptosis in leukemia cells ${ }^{45}$. In addition depletion of GSH, that is a ROS scavenger, increases the effects of vorinostat on AML cells ${ }^{69}$.

3) Other drugs that have been combined with HDAC inhibitors are microtubule stabilizers. VPA increases the toxic effects of paclitaxel in anaplastic thyroid carcinoma cells due to their interaction with the tubulin $\beta$ subunit. VPA enhances tubulin hyperacetylation that stabilizes microtubule structures ${ }^{70}$. Similar enhancement of apoptosis was observed in endometrial carcinoma cells treated with trichostatin A and paclitaxel caused by the activation of the intrinsic mitochondria-dependent pathway. Trichostatin A also stabilizes microtubules via $\alpha$-tubulin acetylation both in vitro and in vivo ${ }^{71}$.

4) Another effective combination of HDAC inhibitors is that with proteasome inhibitors. Cancer cell death due to a combination of proteasome and HDAC inhibitors is caused by induction of oxidative stress, endoplasmic reticulum (ER) stress and stimulations of JNK. Bortezomib, marizomib (NPI-0052) and carfilzomib are proteasome inhibitors which have been combined with HDAC inhibitors. Treatment of multiple myeloma cells with bortezomib made the cells more sensitive to vorinostat and sodium butyrate induced apoptosis ${ }^{72}$. Clinical trials of vorinostat in patients suffering from multiple myeloma demonstrated an increase in its antitumor effects in combination with bortezomib ${ }^{73,74}$. Mechanisms of the anticancer effects of a combination of proteasome and HDAC inhibitors are mitochondrial damage, disruption of aggresome formation, stimulations of JNK and caspases and enhancement of oxidative and ER stress ${ }^{72,75}$. Proteasome inhibitor, marizomib in combination with vorinostat or entinostat increased apoptosis in several leukemia cells, caspase 8 activation and oxidative stress contributed to the synergistic effects ${ }^{45}$. In vitro and in vivo studies with diffuse large B cell lymphoma and mantle cell lymphoma cells including bortezomib resistant ones showed that another proteasome inhibitor, carfilzomib, increased the effects of vorinostat ${ }^{76,77}$.

$5)$ Numerous studies show synergisms or additive effects combining the HDAC inhibitors and DNAdamaging agents such as topoisomerase inhibitors, DNAintercalators, inhibitors of DNA synthesis and agents covalently modifying DNA (i.e. doxorubicin, epirubicin, etoposid, cisplatin, 5-fluorouracil, melphalan, and temozolomide and ionizing radiation in many cancer cell lines) $\left(\right.$ ref. $\left.^{78}\right)$.

\section{CLINICAL STUDIES AND REGISTERED DRUGS}

Several HDAC inhibitors of different structural classes are under clinical development (see Table 1). These include the short-chain fatty acids (phenyl butyrate and val- 
Table 1. HDAC inhibitors under clinical development.

\begin{tabular}{llll}
\hline Chemical structure & Name & HDAC specifity & Study phase \\
\hline Hydroxamates & SAHA (vorinostat) & Pan-inhibitor & $\begin{array}{l}\text { Approved for CTCL, phase III alone } \\
\text { or in combination }\end{array}$ \\
& PXD101 (belinostat) & Pan-inhibitor & Phase II alone or in combination \\
& LBH589 (panobinostat) & Classes I and II & Phase III alone or in combination \\
& ITF2357 (givinostat) & Pan-inhibitor & Phase II alone or in combination \\
& 4SC-201 (resminostat) & Pan-inhibitor & Phase II alone or in combination \\
& PCI 24781 (abexinostat) & Classes I and II & Phase II alone or in combination \\
\hline Cyclic peptides & Depsipeptide/FK228 (romidepsin) & Class I & $\begin{array}{l}\text { Approved for CTCL and PCTL, } \\
\text { phase III alone or in combination }\end{array}$ \\
\hline Benzamides & MS-275 (entinostat) & Class I & Phase II alone or in combination \\
& MGCD0103 (mocetinostat) & Class I & Phase II alone or in combination \\
\hline Aliphatic fatty acids & Valproic acid & Classes I and IIa & $\begin{array}{l}\text { Phase II alone or in combination } \\
\text { (approved for epilepsy and some } \\
\end{array}$ \\
\cline { 2 - 4 } & Butyrate & & $\begin{array}{l}\text { other nonmalignant disseases) } \\
\text { Phase II alone or in combination }\end{array}$ \\
\hline
\end{tabular}

proic acid); the hydroxamic acids [vorinostat (Zolinza ${ }^{\circledR}$, SAHA); panobinostat (LBH589); PCI-24781 and belinostat (PXD101)]; the cyclic tetrapeptides [romidepsin (Istodax $\left.^{\circledR}, \mathrm{FK} 228\right)$; and the benzamides entinostat (MS275)]. Two HDAC inhibitors, vorinostat and romidespin, have been approved by the US FDA for treating patients with progressive, persistent or recurrent cutaneous T-cell lymphoma (CTCL) after one or more lines of chemotherapy and romidepsin for patients suffering from peripheral $\mathrm{T}$ cell lymphoma who received at least one prior therapy ${ }^{79,80}$. Vorinostat had modest activity as a singleagent. Its response rate is $10-20 \%$ in AML and MDS patients. However this HDAC inhibitor, in combination with 5 -azacitidine, increased response rate by $30 \%$. The combination of vorinostat with idarubicin and cytarabine had synergistic activity that was maximal when vorinostat preceded cytarabine. In a phase II trial, the response rate of $85 \%$ of the combination was superior to that of idarubicin and cytarabine alone; notably, there were responses in all patients with FLT3-ITD mutations ${ }^{81,82}$. Phase II trials using administration of vorinostat in refractory cutaneous T-cell lymphoma patients showed an objective response in nearly $30 \%$ of these patients ${ }^{30,83}$. HDAC inhibitors also appear to be active in AML, lymphomas and myelodysplastic syndromes (MDS). Inhibition of HDACs mediates the epigenetic gene silencing in common translocations associated with certain hematological malignancies such as AML/ETO fusion protein ${ }^{84}$. Phase I study of patients with advanced leukemia and MDS treated with vorinostat showed clinical benefit in $17 \%$ (ref. ${ }^{85}$ ). The clinical phase II study proved that panobinostat is an active therapeutic agent in patients with relapsed/refractory Waldenström macroglobulinemia with a response rate of $47 \%\left(\right.$ ref. $\left.{ }^{86}\right)$.

MGCD0103 (Mocetinostat) was evaluated in a clinical phase II trial for the treatment of patients with refrac- tory chronic lymphocytic leukemia (CLL). This HDAC inhibitor alone showed only limited efficacy. For this reason, mocetinostat in combination with other agents such as conventional chemotherapeutic drugs was recommended $^{87}$. LBH-589 (Panobinostat) underwent phase I and II clinical studies for the treatment of solid and hematologic maligancies and phase III clinical trials against CTCL and CML. Two phases I clinical trials showed promising results using $\mathrm{LBH}-589$ in an oral and intravenous form against CTCL (ref. ${ }^{88}$ ) and leukemias, respectively ${ }^{89}$. Both studies found increased acetylation of histones in tumor cells that was associated with apoptosis. LBH-589 also underwent several phase III clinical trials against CTCL too and leukemia in its oral form and showed positive effect for the treatment of those diseases.

Despite promising results in the treatment of CTCL, vorinostat and romidepsin have not been effective in studies that involved solid tumors. Clinical trials have assessed their efficacy against different solid tumors, e.g. neuroendocrine tumors, glioblastoma multiforme, mesothelioma, refractory breast, colorectal, NSCL, prostate, head and neck, renal cell, ovarian, cervical and thyroid cancers. None of the patients included in these trials showed at least partial response to treatment and they suffered from side effects ${ }^{27}$. A study that assessed whether VPA modulates the efficacy of radiochemotherapy with temozolomide in glioblastoma patients showed that combined therapy with VPA was more effective over patients treated without HDAC inhibitors. The authors of this study reasoned that the improvement of in treatment results in the arm with VPA was due to the inhibition of HDAC (ref. ${ }^{90}$ ).

VPA with doxorubicin appeared to be an effective chemotherapy regimen ( $16 \%$ response rate) in patients with refractory or recurrent mesothelioma ${ }^{91}$. Vorinostat 
enhanced the efficacy of carboplatin and paclitaxel in patients with advanced non-small-cell lung cancer ${ }^{92}$. One clinical study showed that the combination of vorinostat and tamoxifen exhibited encouraging activity in reversing hormone resistance of breast cancer ${ }^{93}$.

The most common side effects of HDAC inhibitors are thrombocytopenia, neutropenia, diarrhea, nausea, vomiting and fatigue. Most toxicities are not class-specific and have been observed in all HDAC inhibitors ${ }^{94}$.

\section{CONCLUSIONS AND FUTURE PERSPECTIVES}

It is well known that various HDACs are involved in different pathways and functions in the cell. Nevertheless, additional studies are necessary to disclose other functions of HDACs and determine their cellular interactions. Such studies might result in development of more efficient therapy with HDAC inhibitors that are a promising group of anti-cancer drugs utilized either individually or in combination with other anti-cancer drugs. Of HDAC inhibitors, vorinostat and romidepsin have been approved for cutaneous T-cell lymphoma and romidepsin also for peripheral T-cell lymphoma. Many other HDAC inhibitors are in clinical trial for the treatment of both haematological and solid malignancies. Even though many biological effects of HDAC inhibitors have been found, explanations remain unclear. In addition, their use in combination with other drugs and the schedule of such drug combinations need to be investigated in detail. Indeed, recently, we have found that VPA increased the cytotoxicity of etoposide to neuroblastoma cells in vitro, if etoposide was co-cultivated with VPA but preincubation of these cells with VPA decreased the etoposide efficacy ${ }^{95}$. The discovery of predictive factor(s) is also necessary. Further, one of the most important questions in this field is whether the pan-HDAC inhibitors or the selective inhibitors will be more efficient in different types of cancers.

\section{ABBREVIATIONS}

AML, Acute myelogenous leukemia; CTCL, Cutaneous T-cell lymphoma; DLBCL, Diffuse large B-cell lymphomas; eNOS, Endothelial nitric oxide synthase; FDA, US Food and Drug Administration; FK228, Romidepsin; GNATs, GSK-3 $\beta$, Glycogen synthase kinase$3 \beta$; Gcn5/PCAF $N$-acetyltransferases; HAT, Histone acetyltransferase; HDAC, Histone deacetylase; HIF-1 $\alpha$, Hypoxia inducible factor; Hsp90, Heat shock protein 90; JNK, c-Jun N terminal kinase; LBH589, Panobinostat; MAPK, Mitogen-activated protein kinases; MDS, Myelodysplastic syndromes; MGCD0103, Mocetinostat; NPI-0052, Marizomib; NSCLC, Non small cell lung cancer; PXD-101, Belinostat; ROS, Reactive oxygen species; SAHA, Suberoylanilide hydroxamic acid; SNDX-275, Entinostat; TSA, Trichostatin A; VEGF, Vascular endothelial growth factor; VPA, Valproic acid.

\section{ACKNOWLEDGMENTS}

Supported by GAČR (grant P301/10/0356), by MH CZ - DRO, University Hospital Motol, Prague, Czech Republic 00064203 and Charles University in Prague (UNCE 204025/2012).

\section{CONFLICT OF INTEREST STATEMENT}

The authors state that there are no conflicts of interest regarding the publication of this article.

\section{REFERENCES}

1. Kim HJ, Bae SC. Histone deacetylase inhibitors: molecular mechanisms of action and clinical trials as anti-cancer drugs. Am J Transl Res 2011;3(2):166-79.

2. Marks PA, Richon VM, Miller T, Kelly WK. Histone deacetylase inhibitors. Adv Cancer Res 2004;91:137-68.

3. Roth SY, Allis CD. Histone acetylation and chromatin assembly: a single escort, multiple dances? Cell 1996;87(1):5-8.

4. Spange S, Wagner T, Heinzel T, Kramer OH. Acetylation of non-histone proteins modulates cellular signalling at multiple levels. Int J Biochem Cell Biol 2009;41(1):185-98.

5. Bolden JE, Peart MJ, Johnstone RW. Anticancer activities of histone deacetylase inhibitors. Nat Rev Drug Discov 2006;5(9):769-84.

6. Trapp J, Jung M. The role of NAD+ dependent histone deacetylases (sirtuins) in ageing. Curr Drug Targets 2006;7(11):1553-60.

7. Lee KK, Workman JL. Histone acetyltransferase complexes: one size doesn't fit all. Nat Rev Mol Cell Biol 2007;8(4):284-95.

8. Halkidou K, Gaughan L, Cook S, Leung HY, Neal DE, Robson CN. Upregulation and nuclear recruitment of HDAC1 in hormone refractory prostate cancer. Prostate 2004;59(2):177-89.

9. Choi JH, Kwon HJ, Yoon BI, Kim JH, Han SU, Joo HJ, Kim DY. Expression profile of histone deacetylase 1 in gastric cancer tissues. Jpn J Cancer Res 2001;92(12):1300-4.

10. Zhang Z, Yamashita H, Toyama T, Sugiura H, Ando Y, Mita K, Hamaguchi M, Hara Y, Kobayashi S, Iwase H. Quantitation of HDAC1 mRNA expression in invasive carcinoma of the breast*. Breast Cancer Res Treat 2005;94(1):11-6.

11. Song J, Noh JH, Lee JH, Eun JW, Ahn YM, Kim SY, Lee SH, Park WS, Yoo NJ, Lee JY, Nam SW. Increased expression of histone deacetylase 2 is found in human gastric cancer. APMIS 2005;113(4):264-8.

12. Zhu $P$, Martin E, Mengwasser J, Schlag $P$, Janssen $K P$, Gottlicher $M$. Induction of HDAC2 expression upon loss of APC in colorectal tumorigenesis. Cancer Cell 2004;5(5):455-63.

13. Wilson AJ, Byun DS, Popova N, Murray LB, L'Italien K, Sowa Y, Arango D, Velcich A, Augenlicht LH, Mariadason JM. Histone deacetylase 3 (HDAC3) and other class I HDACs regulate colon cell maturation and p21 expression and are deregulated in human colon cancer. J Biol Chem 2006;281(19):13548-58.

14. Weichert W, Roske A, Niesporek S, Noske A, Buckendahl AC, Dietel M, Gekeler V, Boehm M, Beckers T, Denkert C. Class I histone deacetylase expression has independent prognostic impact in human colorectal cancer: specific role of class I histone deacetylases in vitro and in vivo. Clin Cancer Res 2008;14(6):1669-77.

15. Krishnan M, Singh AB, Smith JJ, Sharma A, Chen X, Eschrich S, Yeatman TJ, Beauchamp RD, Dhawan P. HDAC inhibitors regulate claudin-1 expression in colon cancer cells through modulation of mRNA stability. Oncogene 2010;29(2):305-12.

16. Nakagawa M, Oda Y, Eguchi T, Aishima S, Yao T, Hosoi F, Basaki Y, Ono M, Kuwano M, Tanaka M, Tsuneyoshi M. Expression profile of class I histone deacetylases in human cancer tissues. Oncol Rep 2007;18(4):769-74.

17. Oehme I, Deubzer HE, Wegener D, Pickert D, Linke JP, Hero B, KoppSchneider A, Westermann F, Ulrich SM, von Deimling A, Fischer M, Witt O. Histone deacetylase 8 in neuroblastoma tumorigenesis. Clin Cancer Res 2009;15(1):91-9. 
18. Noonan EJ, Place RF, Pookot D, Basak S, Whitson JM, Hirata H, Giardina C, Dahiya R. miR-449a targets HDAC-1 and induces growth arrest in prostate cancer. Oncogene 2009;28(14):1714-24.

19. Zhang J, Yang Y, Yang T, Liu Y, Li A, Fu S, Wu M, Pan Z, Zhou W. microRNA-22, downregulated in hepatocellular carcinoma and correlated with prognosis, suppresses cell proliferation and tumourigenicity. Br J Cancer 2010;103(8):1215-20.

20. Marquard L, Poulsen CB, Gjerdrum LM, de Nully Brown P, Christensen IJ, Jensen PB, Sehested M, Johansen P, Ralfkiaer E. Histone deacetylase 1, 2, 6 and acetylated histone H4 in B- and T-cell lymphomas. Histopathology 2009;54(6):688-98.

21. Adams H, Fritzsche FR, Dirnhofer S, Kristiansen G, Tzankov A. Class I histone deacetylases 1, 2 and 3 are highly expressed in classica Hodgkin's lymphoma. Expert Opin Ther Targets 2010;14(6):577-84.

22. Roccaro AM, Sacco A, Jia X, Azab AK, Maiso P, Ngo HT, Azab F, Runnels J, Quang P, Ghobrial IM. microRNA-dependent modulation of histone acetylation in Waldenstrom macroglobulinemia. Blood 2010;116(9):1506-14

23. Zupkovitz G, Tischler J, Posch M, Sadzak I, Ramsauer K, Egger G, Grausenburger R, Schweifer N, Chiocca S, Decker T, Seiser C. Negative and positive regulation of gene expression by mouse histone deacetylase 1. Mol Cell Biol 2006;26(21):7913-28.

24. Montgomery RL, Davis CA, Potthoff MJ, Haberland M, Fielitz J, Qi X Hill JA, Richardson JA, Olson EN. Histone deacetylases 1 and 2 redundantly regulate cardiac morphogenesis, growth, and contractility. Genes Dev 2007;21(14):1790-802.

25. Sjoblom T, Jones S, Wood LD, Parsons DW, Lin J, Barber TD, Mandelker D, Leary RJ, Ptak J, Silliman N, Szabo S, Buckhaults P, Farrell C, Meeh P, Markowitz SD, Willis J, Dawson D, Willson JK, Gazdar AF, Hartigan J, Wu L, Liu C, Parmigiani G, Park BH, Bachman KE, Papadopoulos $\mathrm{N}$, Vogelstein B, Kinzler KW, Velculescu VE. The consensus coding sequences of human breast and colorectal cancers. Science 2006;314(5797):268-74.

26. Ropero $S$, Fraga MF, Ballestar E, Hamelin R, Yamamoto $H$, BoixChornet M, Caballero R, Alaminos M, Setien F, Paz MF, Herranz M Palacios J, Arango D, Orntoft TF, Aaltonen LA, Schwartz S, Jr., Esteller $M$. A truncating mutation of HDAC2 in human cancers confers resistance to histone deacetylase inhibition. Nat Genet 2006:38(5):566-9.

27. Gryder BE, Sodji QH, Oyelere AK. Targeted cancer therapy: giving histone deacetylase inhibitors all they need to succeed. Future Med Chem 2012;4(4):505-24.

28. Andrews KT, Tran TN, Fairlie DP. Towards histone deacetylase inhibitors as new antimalarial drugs. Curr Pharm Des 2012;18(24):3467-79.

29. Royce SG, Ververis K, Karagiannis TC. Histone deacetylase inhibitors: can we consider potent anti-neoplastic agents for the treatment of asthma? Ann Clin Lab Sci 2012;42(3):338-45.

30. Duvic M, Talpur R, Ni X, Zhang C, Hazarika P, Kelly C, Chiao JH, Reilly $J$ J, Ricker JL, Richon VM, Frankel SR. Phase 2 trial of oral vorinosta (suberoylanilide hydroxamic acid, SAHA) for refractory cutaneous T-cell lymphoma (CTCL). Blood 2007;109(1):31-9.

31. Xu WS, Parmigiani RB, Marks PA. Histone deacetylase inhibitors: molecular mechanisms of action. Oncogene 2007;26(37):5541-52.

32. Dell'Aversana C, Lepore I, Altucci L. HDAC modulation and cell death in the clinic. Exp Cell Res 2012;318(11):1229-44.

33. Campas-Moya C. Romidepsin for the treatment of cutaneous T-cell lymphoma. Drugs Today (Barc) 2009;45(11):787-95.

34. Furumai R, Matsuyama A, Kobashi N, Lee KH, Nishiyama M, Nakajima H, Tanaka A, Komatsu Y, Nishino N, Yoshida M, Horinouchi S. FK228 (depsipeptide) as a natural prodrug that inhibits class I histone deacetylases. Cancer Res 2002;62(17):4916-21.

35. Mariadason JM, Corner GA, Augenlicht LH. Genetic reprogramming in pathways of colonic cell maturation induced by short chain fatty acids: comparison with trichostatin A, sulindac, and curcumin and implications for chemoprevention of colon cancer. Cancer Res 2000;60(16):4561-72

36. Eyupoglu IY, Hahnen E, Trankle C, Savaskan NE, Siebzehnrubl FA, Buslei R, Lemke D, Wick W, Fahlbusch R, Blumcke I. Experimental therapy of malignant gliomas using the inhibitor of histone deacetylase MS-275. Mol Cancer Ther 2006;5(5):1248-55.

37. Minucci S, Pelicci PG. Histone deacetylase inhibitors and the promise of epigenetic (and more) treatments for cancer. Nat Rev Cancer 2006;6(1):38-51.

38. Michaelis M, Michaelis UR, Fleming I, Suhan T, Cinatl J, Blaheta RA, Hoffmann K, Kotchetkov R, Busse R, Nau H, Cinatl J, Jr. Valproic acid inhibits angiogenesis in vitro and in vivo. Mol Pharmacol 2004;65(3):520-7.

39. Richon VM, Sandhoff TW, Rifkind RA, Marks PA. Histone deacetylase inhibitor selectively induces p21WAF1 expression and gene-associated histone acetylation. Proc Natl Acad Sci U S A 2000;97(18):100149 .

40. Ocker M, Schneider-Stock R. Histone deacetylase inhibitors: signalling towards p21cip1/waf1. Int J Biochem Cell Biol 2007;39(78):1367-74.

41. Gius D, Cui H, Bradbury CM, Cook J, Smart DK, Zhao S, Young L, Brandenburg SA, Hu Y, Bisht KS, Ho AS, Mattson D, Sun L, Munson PJ, Chuang EY, Mitchell JB, Feinberg AP. Distinct effects on gene expression of chemical and genetic manipulation of the cancer epigenome revealed by a multimodality approach. Cancer Cell 2004;6(4):361-71.

42. Qiu L, Burgess A, Fairlie DP, Leonard H, Parsons PG, Gabrielli BG. Histone deacetylase inhibitors trigger a G2 checkpoint in normal cells that is defective in tumor cells. Mol Biol Cell 2000;11(6):2069-83.

43. Yuan PX, Huang LD, Jiang YM, Gutkind JS, Manji HK, Chen G. The mood stabilizer valproic acid activates mitogen-activated protein kinases and promotes neurite growth. J Biol Chem 2001;276(34):31674-83.

44. Leppa S, Eriksson M, Saffrich R, Ansorge W, Bohmann D. Complex functions of AP-1 transcription factors in differentiation and survival of PC12 cells. Mol Cell Biol 2001;21(13):4369-78.

45. Miller CP, Singh MM, Rivera-Del Valle N, Manton CA, Chandra J. Therapeutic strategies to enhance the anticancer efficacy of histone deacetylase inhibitors. J Biomed Biotechnol 2011;2011:514261.

46. Fulda S. Modulation of TRAIL-induced apoptosis by HDAC inhibitors. Curr Cancer Drug Targets 2008;8(2):132-40.

47. Gao S, Mobley A, Miller C, Boklan J, Chandra J. Potentiation of reactive oxygen species is a marker for synergistic cytotoxicity of MS-275 and 5-azacytidine in leukemic cells. Leuk Res 2008;32(5):771-80.

48. Ungerstedt JS, Sowa Y, Xu WS, Shao Y, Dokmanovic M, Perez G, Ngo L, Holmgren A, Jiang X, Marks PA. Role of thioredoxin in the response of normal and transformed cells to histone deacetylase inhibitors. Proc Natl Acad Sci U S A 2005;102(3):673-8.

49. Hrebackova J, Hrabeta J, Eckschlager T. Valproic acid in the complex therapy of malignant tumors. Curr Drug Targets 2010;11(3):361-79.

50. Oh M, Choi IK, Kwon HJ. Inhibition of histone deacetylase1 induces autophagy. Biochem Biophys Res Commun 2008;369(4):1179-83.

51. Chiao MT, Cheng WY, Yang YC, Shen CC, Ko JL. Suberoylanilide hydroxamic acid (SAHA) causes tumor growth slowdown and triggers autophagy in glioblastoma stem cells. Autophagy 2013;9(10).

52. Logan CY, Nusse R. The Wnt signaling pathway in development and disease. Annu Rev Cell Dev Biol 2004;20:781-810.

53. Kramer OH, Zhu P, Ostendorff HP, Golebiewski M, Tiefenbach J, Peters MA, Brill B, Groner B, Bach I, Heinzel T, Gottlicher M. The histone deacetylase inhibitor valproic acid selectively induces proteasomal degradation of HDAC2. EMBO J 2003;22(13):3411-20.

54. Montgomery RL, Potthoff MJ, Haberland M, Qi X, Matsuzaki S, Humphries KM, Richardson JA, Bassel-Duby R, Olson EN. Maintenance of cardiac energy metabolism by histone deacetylase 3 in mice. J Clin Invest 2008;118(11):3588-97.

55. Cinatl J, Jr., Kotchetkov R, Blaheta R, Driever PH, Vogel JU, Cinatl $\mathrm{J}$. Induction of differentiation and suppression of malignant phenotype of human neuroblastoma $\mathrm{BE}(2)-\mathrm{C}$ cells by valproic acid: enhancement by combination with interferon-alpha. Int J Oncol 2002;20(1):97-106.

56. Jeong JW, Bae MK, Ahn MY, Kim SH, Sohn TK, Bae MH, Yoo MA, Song EJ, Lee KJ, Kim KW. Regulation and destabilization of HIF-1alpha by ARD1-mediated acetylation. Cell 2002;111(5):709-20.

57. Bali P, Pranpat M, Bradner J, Balasis M, Fiskus W, Guo F, Rocha K, Kumaraswamy S, Boyapalle S, Atadja P, Seto E, Bhalla K. Inhibition of histone deacetylase 6 acetylates and disrupts the chaperone function of heat shock protein 90: a novel basis for antileukemia activity of histone deacetylase inhibitors. J Biol Chem 2005;280(29):2672934.

58. Namdar M, Perez G, Ngo L, Marks PA. Selective inhibition of histone deacetylase 6 (HDAC6) induces DNA damage and sensitizes transformed cells to anticancer agents. Proc Natl Acad Sci U S A 2010;107(46):20003-8.

59. Ma X, Ezzeldin HH, Diasio RB. Histone deacetylase inhibitors: current status and overview of recent clinical trials. Drugs 2009;69(14):191134. 
60. Griffiths EA, Gore SD. DNA methyltransferase and histone deacetylase inhibitors in the treatment of myelodysplastic syndromes. Semin Hematol 2008;45(1):23-30.

61. Rudek MA, Zhao M, He P, Hartke C, Gilbert J, Gore SD, Carducci MA Baker SD. Pharmacokinetics of 5-azacitidine administered with phenylbutyrate in patients with refractory solid tumors or hematologic malignancies. J Clin Oncol 2005;23(17):3906-11.

62. Chen MY, Liao WS, Lu Z, Bornmann WG, Hennessey V, Washington MN, Rosner GL, YuY, Ahmed AA, Bast RC, Jr. Decitabine and suberoylanilide hydroxamic acid (SAHA) inhibit growth of ovarian cancer cell lines and xenografts while inducing expression of imprinted tumor suppressor genes, apoptosis, G2/M arrest, and autophagy. Cancer 2011;117(19):4424-38.

63. Cecconi D, Donadelli M, Dalla Pozza E, Rinalducci S, Zolla L, Scupoli MT, Righetti PG, Scarpa A, Palmieri M. Synergistic effect of trichostatin A and 5-aza-2'-deoxycytidine on growth inhibition of pancreatic endocrine tumour cell lines: a proteomic study. Proteomics 2009;9(7):1952-66.

64. Walton TJ, Li G, Seth R, McArdle SE, Bishop MC, Rees RC. DNA demethylation and histone deacetylation inhibition co-operate to reexpress estrogen receptor beta and induce apoptosis in prostate cancer cell-lines. Prostate 2008;68(2):210-22.

65. Yang H, Hoshino K, Sanchez-Gonzalez B, Kantarjian H, Garcia-Manero G. Antileukemia activity of the combination of 5-aza-2'-deoxycytidine with valproic acid. Leuk Res 2005;29(7):739-48.

66. Ecke I, Petry F, Rosenberger A, Tauber S, Monkemeyer S, Hess I, Dullin C, Kimmina S, Pirngruber J, Johnsen SA, Uhmann A, Nitzki F, Wojnowski L, Schulz-Schaeffer W, Witt O, Hahn H. Antitumor effects of a combined 5-aza-2'deoxycytidine and valproic acid treatment on rhabdomyosarcoma and medulloblastoma in Ptch mutant mice. Cancer Res 2009;69(3):887-95.

67. Klisovic MI, Maghraby EA, Parthun MR, Guimond M, Sklenar AR Whitman SP, Chan KK, Murphy T, Anon J, Archer KJ, Rush LJ, Plass C, Grever MR, Byrd JC, Marcucci G. Depsipeptide (FR 901228) promotes histone acetylation, gene transcription, apoptosis and its activity is enhanced by DNA methyltransferase inhibitors in AML1/ETOpositive leukemic cells. Leukemia 2003;17(2):350-8.

68. Chai G, Li L, Zhou W, Wu L, Zhao Y, Wang D, Lu S, Yu Y, Wang $H$, McNutt MA, Hu YG, Chen Y, Yang Y, Wu X, Otterson GA, Zhu WG. HDAC inhibitors act with 5-aza-2'-deoxycytidine to inhibit cell proliferation by suppressing removal of incorporated abases in lung cancer cells. PLoS One 2008;3(6):e2445.

69. Hu Y, Lu W, Chen G, Zhang H, Jia Y, Wei Y, Yang H, Zhang W, Fiskus W, Bhalla K, Keating M, Huang P, Garcia-Manero G. Overcoming resistance to histone deacetylase inhibitors in human leukemia with the redox modulating compound beta-phenylethyl isothiocyanate. Blood 2010;116(15):2732-41.

70. Catalano MG, Poli R, Pugliese M, Fortunati N, Boccuzzi G. Valproic acid enhances tubulin acetylation and apoptotic activity of paclitaxel on anaplastic thyroid cancer cell lines. Endocr Relat Cancer 2007;14(3):839-45.

71. Dowdy SC, Jiang S, Zhou XC, Hou X, Jin F, Podratz KC, Jiang SW. Histone deacetylase inhibitors and paclitaxel cause synergistic effects on apoptosis and microtubule stabilization in papillary serous endometrial cancer cells. Mol Cancer Ther 2006;5(11):2767-76.

72. Pei $X Y$, Dai $Y$, Grant S. Synergistic induction of oxidative injury and apoptosis in human multiple myeloma cells by the proteasome inhibitor bortezomib and histone deacetylase inhibitors. Clin Cancer Res 2004;10(11):3839-52.

73. Badros A, Burger AM, Philip S, Niesvizky R, Kolla SS, Goloubeva O, Harris C, Zwiebel J, Wright JJ, Espinoza-Delgado I, Baer MR, Holleran J, Egorin MJ, Grant S. Phase I study of vorinostat in combination with bortezomib for relapsed and refractory multiple myeloma. Clin Cancer Res 2009;15(16):5250-7.

74. Mazumder A, Vesole DH, Jagannath S. Vorinostat plus bortezomib for the treatment of relapsed/refractory multiple myeloma: a case series illustrating utility in clinical practice. Clin Lymphoma Myeloma Leuk 2010;10(2):149-51.

75. Nawrocki ST, Carew JS, Pino MS, Highshaw RA, Andtbacka RH, Dunner K, Jr., Pal A, Bornmann WG, Chiao PJ, Huang P, Xiong $\mathrm{H}_{\text {, }}$ Abbruzzese JL, McConkey DJ. Aggresome disruption: a novel strategy to enhance bortezomib-induced apoptosis in pancreatic cancer cells. Cancer Res 2006;66(7):3773-81.
76. Dasmahapatra G, Lembersky D, Kramer L, Fisher RI, Friedberg J, Dent $\mathrm{P}$, Grant $\mathrm{S}$. The pan-HDAC inhibitor vorinostat potentiates the activity of the proteasome inhibitor carfilzomib in human DLBCL cells in vitro and in vivo. Blood 2010;115(22):4478-87.

77. Dasmahapatra G, Lembersky D, Son MP, Attkisson E, Dent P, Fisher RI, Friedberg JW, Grant S. Carfilzomib interacts synergistically with histone deacetylase inhibitors in mantle cell lymphoma cells in vitro and in vivo. Mol Cancer Ther 2011;10(9):1686-97.

78. Stiborova M, Eckschlager T, Poljakova J, Hrabeta J, Adam V, Kizek R, Frei $\mathrm{E}$. The synergistic effects of DNA-targeted chemotherapeutics and histone deacetylase inhibitors as therapeutic strategies for cancer treatment. Curr Med Chem 2012;19(25):4218-38.

79. Khan O, La Thangue NB. Drug Insight: histone deacetylase inhibitor-based therapies for cutaneous T-cell lymphomas. Nat Clin Pract Oncol 2008;5(12):714-26.

80. Whittaker SJ, Demierre MF, Kim EJ, Rook AH, Lerner A, Duvic M, Scarisbrick J, Reddy S, Robak T, Becker JC, Samtsov A, McCulloch W, Kim YH. Final results from a multicenter, international, pivotal study of romidepsin in refractory cutaneous T-cell lymphoma. J Clin Oncol 2010;28(29):4485-91.

81. Garcia-Manero G, Tambaro FP, Bekele NB, Yang H, Ravandi F, Jabbour E, Borthakur G, Kadia TM, Konopleva MY, Faderl S, Cortes JE, Brandt M, Hu Y, McCue D, Newsome WM, Pierce SR, de Lima M, Kantarjian HM. Phase II trial of vorinostat with idarubicin and cytarabine for patients with newly diagnosed acute myelogenous leukemia or myelodysplastic syndrome. J Clin Oncol 2012;30(18):2204-10.

82. Khan I, Altman JK, Licht JD. New strategies in acute myeloid leukemia: redefining prognostic markers to guide therapy. Clin Cancer Res 2012;18(19):5163-71.

83. Olsen EA, Kim YH, Kuzel TM, Pacheco TR, Foss FM, Parker S, Frankel SR, Chen C, Ricker JL, Arduino JM, Duvic M. Phase Ilb multicenter trial of vorinostat in patients with persistent, progressive, or treatment refractory cutaneous T-cell lymphoma. J Clin Oncol 2007;25(21):310915.

84. Blum W, Marcucci G. Targeting epigenetic changes in acute myeloid leukemia. Clin Adv Hematol Oncol 2005;3(11):855-65, 82.

85. Garcia-Manero G, Yang H, Bueso-Ramos C, Ferrajoli A, Cortes J, Wierda WG, Faderl S, Koller C, Morris G, Rosner G, Loboda A, Fantin VR, Randolph SS, Hardwick JS, Reilly JF, Chen C, Ricker JL, Secrist JP, Richon VM, Frankel SR, Kantarjian HM. Phase 1 study of the histone deacetylase inhibitor vorinostat (suberoylanilide hydroxamic acid [SAHA]) in patients with advanced leukemias and myelodysplastic syndromes. Blood 2008;111(3):1060-6.

86. Ghobrial IM, Campigotto F, Murphy TJ, Boswell EN, Banwait R, Azab F, Chuma S, Kunsman J, Donovan A, Masood F, Warren D, Rodig S, Anderson KC, Richardson PG, Weller E, Matous J. Results of a phase 2 trial of the single-agent histone deacetylase inhibitor panobinostat in patients with relapsed/refractory Waldenstrom macroglobulinemia. Blood 2013;121(8):1296-303.

87. Blum KA, Advani A, Fernandez L, Van Der Jagt R, Brandwein J, Kambhampati S, Kassis J, Davis M, Bonfils C, Dubay M, Dumouchel J, Drouin M, Lucas DM, Martell RE, Byrd JC. Phase II study of the histone deacetylase inhibitor MGCD0103 in patients with previously treated chronic lymphocytic leukaemia. Br J Haematol 2009;147(4):507-14.

88. Ellis L, Bots M, Lindemann RK, Bolden JE, Newbold A, Cluse LA, Scott CL, Strasser A, Atadja P, Lowe SW, Johnstone RW. The histone deacetylase inhibitors LAQ824 and LBH589 do not require death receptor signaling or a functional apoptosome to mediate tumor cell death or therapeutic efficacy. Blood 2009;114(2):380-93.

89. Giles F, Fischer T, Cortes J, Garcia-Manero G, Beck J, Ravandi F Masson E, Rae P, Laird G, Sharma S, Kantarjian H, Dugan M, Albitar $M$, Bhalla K. A phase I study of intravenous LBH589, a novel cinnamic hydroxamic acid analogue histone deacetylase inhibitor, in patients with refractory hematologic malignancies. Clin Cancer Res 2006;12(15):4628-35.

90. Weller M, Gorlia T, Cairncross JG, van den Bent MJ, Mason W, Belanger K, Brandes AA, Bogdahn U, Macdonald DR, Forsyth P, Rossetti AO, Lacombe D, Mirimanoff RO, Vecht CJ, Stupp R. Prolonged survival with valproic acid use in the EORTC/NCIC temozolomide trial for glioblastoma. Neurology 2011;77(12):1156-64.

91. Scherpereel A, Berghmans T, Lafitte JJ, Colinet B, Richez M, Bonduelle Y, Meert AP, Dhalluin X, Leclercq N, Paesmans M, Willems L, Sculier JP. Valproate-doxorubicin: promising therapy for progressing mesothelioma. A phase II study. Eur Respir J 2011;37(1):129-35. 
92. Ramalingam SS, Maitland ML, Frankel $P$, Argiris AE, Koczywas $M$ Gitlitz B, Thomas S, Espinoza-Delgado I, Vokes EE, Gandara DR, Belan CP. Carboplatin and Paclitaxel in combination with either vorinostat or placebo for first-line therapy of advanced non-small-cell lung cancer. J Clin Oncol 2010;28(1):56-62.

93. Munster PN, Thurn KT, Thomas S, Raha P, Lacevic M, Miller A, Melisko M, Ismail-Khan R, Rugo H, Moasser M, Minton SE. A phase Il study of the histone deacetylase inhibitor vorinostat combined with tamoxi- fen for the treatment of patients with hormone therapy-resistant breast cancer. Br J Cancer 2011;104(12):1828-35.

94. Thurn KT, Thomas S, Moore A, Munster PN. Rational therapeutic combinations with histone deacetylase inhibitors for the treatment of cancer. Future Oncol 2011;7(2):263-83.

95. Groh T, Hrabeta J, Poljakova J, Eckschlager T, Stiborova M. Impact of histone deacetylase inhibitor valproic acid on the anticancer effect of etoposide on neuroblastoma cells. Neuro Endocrinol Lett 2012;33 Suppl 3:16-24. 